\title{
Autonomy, intimate partner violence, and maternal health-seeking behavior: Findings from mixed-methods analysis in Ethiopia
}

Charlotte E. Warren

Population Council

Pooja Sripad

Population Council

Charity Ndwiga

Population Council

Follow this and additional works at: https://knowledgecommons.popcouncil.org/departments_sbsr-rh

Part of the Demography, Population, and Ecology Commons, Domestic and Intimate Partner Violence Commons, Family, Life Course, and Society Commons, Gender and Sexuality Commons, International Public Health Commons, Maternal and Child Health Commons, and the Medicine and Health Commons How does access to this work benefit you? Let us know!

\section{Recommended Citation}

Warren, Charlotte E., Pooja Sripad, and Charity Ndwiga. 2019. "Autonomy, intimate partner violence, and maternal health-seeking behavior: Findings from mixed-methods analysis in Ethiopia," Ending Eclampsia Country Brief. Washington, DC: Population Council. 


\section{ENDING \\ Eclampsia}

Autonomy, Intimate Partner Violence, and Maternal Health-Seeking Behavior: Findings from MixedMethods Analysis in Ethiopia

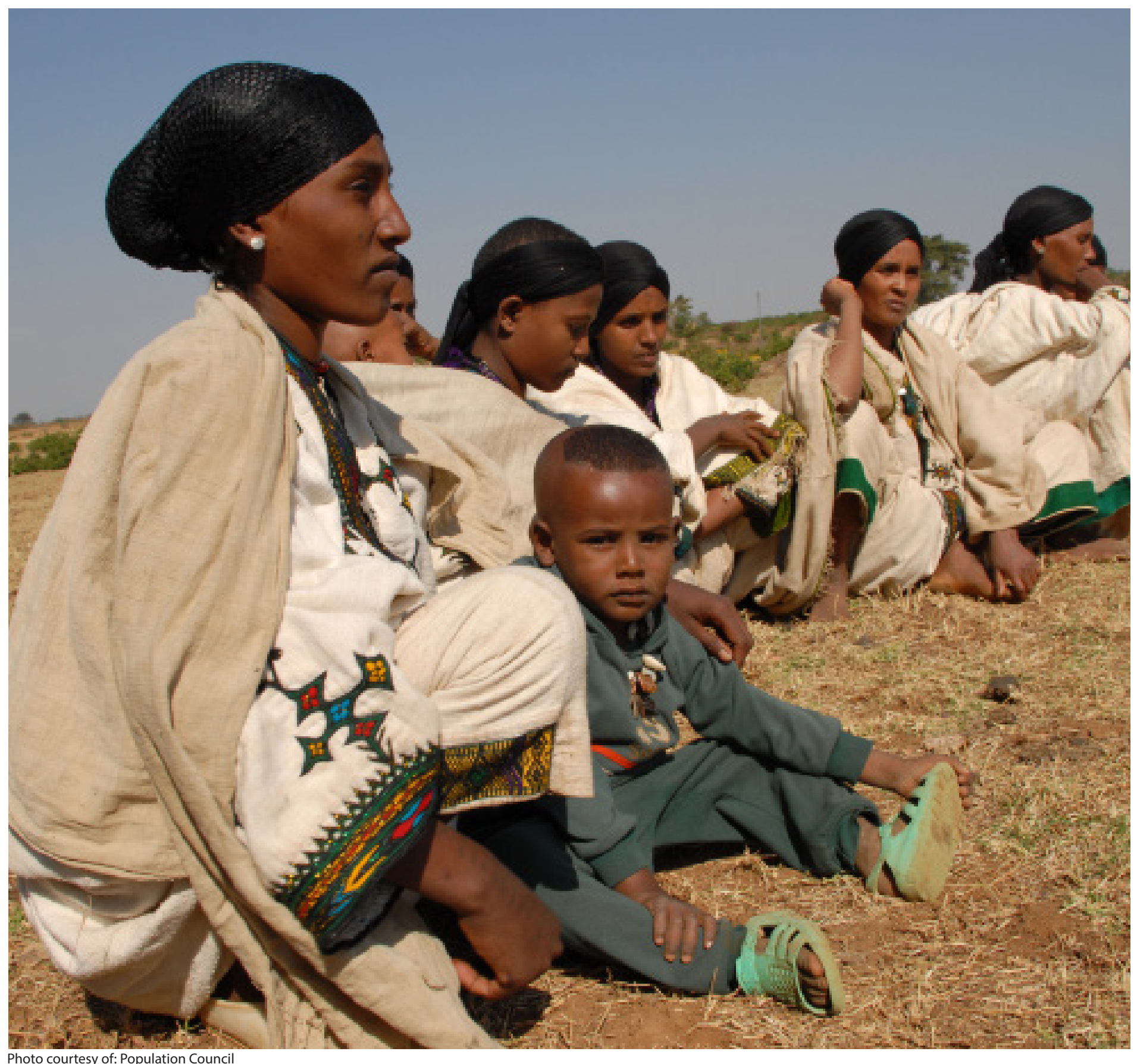

The Population Council conducts research and delivers solutions that improve lives around the world. Big ideas supported by evidence: It's our model for global change. popcouncil.org

(c) 2019 The Population Council, Inc.

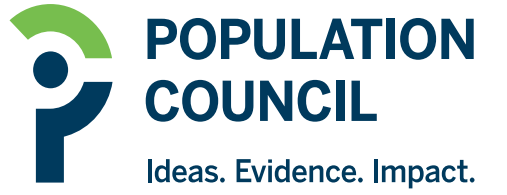




\section{BACKGROUND}

Gendered norms and discriminatory practices often limit women's decision-making power, which over time can lead to social norms that systematically disadvantage women.

Aspects of empowerment, a multi-faceted construct, were explored in a global evaluation of Demographic and Health Survey (DHS) data, that measured how gendered social norms influenced maternal healthseeking behaviors. Analysis specifically explored associations of women's autonomy and acceptability of intimate partner violence against women (IPVAW) on antenatal care (ANC) use and facility delivery in 63 low- and middle-income countries. Service utilization is positively associated with increased autonomy and negatively associated with increased acceptability of IPVAW, but variability exists across countries and regions. There is need to explore complexities of gender in specific contexts.

In Ethiopia, maternal health-seeking behaviors are influenced by numerous interrelated factors. Little research exists on how gender dynamics and norms, including acceptability of various forms of IPVAW, may influence women's decision-making autonomy, health-seeking behavior, and overall well-being.

The purpose of this study was to explore the relationship between women's autonomy and acceptability of IPVAW and two primary maternal health care utilization outcomes: ANC use and facility delivery.

This brief highlights quantitative and qualitative findings on the relationship between women's autonomy and IPVAW acceptability and maternal health seeking behaviors in Ethiopia.

\section{METHODS}

We applied a mixed methods approach to explore gender dynamics. We drew on a secondary analysis of aggregate DHS data in Ethiopia from 2005 to 2016 and 17 in-depth interviews with women who had experienced and survived pre-eclampsia. We also conducted eight focus group discussions with community men and women in rural and urban areas of Sidama Zone in the Southern Nations, Nationalities, and Peoples Region (SNNPR).

Scales developed for women's autonomy (3-item) and acceptability of IPVAW (5-item) indicate women's contribution to decision-making around various aspects of their lives and accepting attitudes toward a husband beating his wife for different reasons.

Multivariable logistic regressions estimate associations between these scores and the primary outcomes, controlling for age, wealth, education, marital status, birth order, child sex, urban/rural residence and quality of care at the individual level and average wealth and educational attainment at the cluster level.

Qualitative analyses involved transcription and translation of interviews, applying an inductivelyderived codebook using NVivo, and triangulating findings with DHS results.

\section{RESULTS}

Combined DHS data from the 2005, 2011, and 2016 surveys yielded a sample of 20,882 women and 21,169 births. We found that $16.6 \%$ of women had facility-based deliveries and $2.1 \%$ received their recommended eight ANC visits (Table 1).

Compared to global maternal health-seeking behaviors, women in Ethiopia are less likely to deliver in facilities and receive their eight recommended ANC visits ( $60 \%$ and $17 \%$ of women globally, respectively). Tables 2 and 3 describe the child-level and quality covariates. 
Table 1. Descriptive Statistics, Mother-Level Outcomes and Covariates, Ethiopia, 2005, 2011, 2016

\begin{tabular}{|c|c|c|c|c|c|}
\hline & Mean & SD & No. Cases & Min & Max \\
\hline \multicolumn{6}{|l|}{ Mother-Level Outcomes } \\
\hline Delivery in a health facility ( $1=$ yes $)$ & 0.166 & & 3,466 & & \\
\hline WHO Recommended 8 ANC Visits (1 = yes) & 0.021 & & 439 & & \\
\hline \multicolumn{6}{|l|}{ Mother-Level Covariates } \\
\hline Wealth, quintiles & 2.620 & 1.404 & & 1 & 5 \\
\hline Maternal education, none (1=yes) & 0.693 & & 14,471 & & \\
\hline Maternal education, primary (1=yes) & 0.247 & & 5,158 & & \\
\hline Maternal education, secondary (1=yes) & 0.043 & & 898 & & \\
\hline Maternal education, higher (1=yes) & 0.018 & & 376 & & \\
\hline Maternal age, years & 29.392 & 7.071 & & 15 & 49 \\
\hline Marital status (1=married) & 0.898 & & 18,752 & & \\
\hline Urban (1=yes) & 0.122 & & 2,548 & & \\
\hline \multicolumn{6}{|l|}{ Cluster-Level Covariates } \\
\hline Average wealth, quintiles & 2.612 & 1.110 & & 1 & 5 \\
\hline Average education, highest level & 0.373 & 0.411 & & 0 & 3 \\
\hline $\begin{array}{l}\mathbf{N} \\
\text { Notes: Each observation corresponds to a wom }\end{array}$ & 20,882 & & & & \\
\hline
\end{tabular}

\begin{tabular}{|c|c|c|c|c|c|}
\hline & Mean & SD & No. Cases & Min & Max \\
\hline \multicolumn{6}{|l|}{ Child-Level Covariates } \\
\hline Birth order & 4.184 & 2.656 & & 1 & 18 \\
\hline Multiple birth $(1=$ yes $)$ & 0.012 & & 251 & & \\
\hline Child sex $(1=$ male $)$ & 0.517 & & 10,796 & & \\
\hline
\end{tabular}

\section{Table 3. Descriptive Statistics, Child-Level Covariates, Ethiopia, 2005, 2011, 2016}

\begin{tabular}{|l|c|c|}
\hline & Mean & No. Cases \\
\hline Quality Covariates & 0.065 & 1,376 \\
\hline Checked weight at pregnancy (1 = yes) & 0 & 0 \\
\hline Checked height at pregnancy (1 = yes) & 0.319 & 6,753 \\
\hline Checked blood pressure at pregnancy (1 = yes) & 0.222 & 4,700 \\
\hline Took urine sample at pregnancy (1 = yes) & 0.254 & 5,377 \\
\hline Took blood sample at pregnancy (1 = yes) & 0.152 & 3,218 \\
\hline Told about pregnancy complications (1 = yes) & 0.025 & 529 \\
\hline Told where to go for complications (1 = yes) & 0.053 & 1,122 \\
\hline Health professional checked after delivery (1 = yes) & 0.136 & 2,879 \\
\hline Quality score (0 - 1, percent out of 8) & 0.148 & 3,133 \\
\hline Quality score, prenatal (0 - 1, percent out of 7) & $\mathbf{2 1 , 1 6 9}$ & \\
\hline $\mathbf{N}$ & & \\
Notes: Each observation corresponds to a birth. & & \\
\hline
\end{tabular}


In the Ethiopia sample, $67 \%$ of women report involvement in decision-making regarding their own health care utilization, and $60 \%$ were involved in household purchases; $73 \%$ in visiting relatives; and $16.5 \%$ were involved in decisions related to money. Overall, $40.4 \%$ of women in Ethiopia report involvement in any decision-making (Table 4).

Relatedly, $54.4 \%$ of women believe that a husband is justified in beating his wife for at least one of several reasons (Table 4). Proportions of women's autonomy (measured using decision-making power as proxy) were similar to global estimates (40.1\%), while acceptability of IPVAW was higher in Ethiopia (compared to $24.8 \%$ of women globally) (1).

Compared to global positive assoiciations, in Ethiopia, the magnitude of autonomy associations are similar; increased women's autonomy increased the likelihood of facility delivery (Ethiopia OR: 1.683, Global OR: 1.3, p<0.01) and the receipt of eight WHO-recommended ANC visits (Ethiopia OR: 1.476, Global OR: 1.4, $p<0.01$ ). Ethiopian associations of acceptability of IPVAW with service utilization were similar to global trends; women in Ethiopia with higher IPVAW scores were less likely than women globally to deliver in facilities (Ethiopia OR: 0.749, Global OR:0.911, $p<0.01$ ), though slightly more likely to achieve eight ANC visits (Ethiopia OR: 0.857, Global OR: 0.797, p<0.01) (Table 5). While some variation in ANC use emerged, younger women (74\%), urban women (90\%), and women with secondary and above education (94\%) tended to express greater senses of empowerment in their own health decision-making (1). Qualitative data corroborate that the majority of women have individual autonomy over their own health care decisions.

"I decide by myself and come to the health facility. Prevously, people have had different ideas, but I do not follow that."

IDI, pre-eclampsia survivor, rural

"Anything that happens to my body affects only me. Therefore, nobody can make decisions on my life. Sometimes [my husband] encourages and helps me... he comes with me, gives me transportation money... [HEWs] encourage and counsel us when we go there for [pregnancy] checkups. They even remind us of checkup days."

FGD, female participant, rural

Descriptions of feeling personally empowered to make health-related decisions were often tempered by significant social influences from spouses, mothersin-law, family members, HEWs, community members, cultural leaders, and assorted government-supported women's groups. Supportive husbands and women's groups provided encouragement to attend ANC, but traditional wisdom and apprehension from mothersin-law and community members were frequently seen as a deterrent.

Table 4. Distribution of Autonomy and Acceptability of IPVAW Covariates, Ethiopia, 2005, 2011, 2016

\begin{tabular}{|l|c|c|}
\hline \multicolumn{2}{|l|}{ Mean } & No. Cases \\
\hline Autonomy & 0.165 & 3,446 \\
\hline Respondent involved in decisions over money (1 = yes) & 0.671 & 14,012 \\
\hline Respondent involved in decisions over own healthcare (1 = yes) & 0.606 & 12,654 \\
\hline Respondent involved in decisions over household purchases (1 = yes) & 0.248 & 5,179 \\
\hline Respondent involved in decisions over daily purchases (1 = yes) & 0.733 & 15,307 \\
\hline Respondent involved in decisions over visiting relatives (1 = yes) & 0 & 0 \\
\hline Respondent involved in decisions over cooking food (1 = yes) & 0.404 & 8,436 \\
\hline Woman autonomy score (0 - 1, percent out of 6) & 0.564 & 11,777 \\
\hline Acceptability of IPVAW & 0.598 & 12,487 \\
\hline Beating justified if wife goes out without telling husband (1 = yes) & 0.546 & 11,402 \\
\hline Beating justified if wife neglects children (1 = yes) & 0.455 & 9,501 \\
\hline Beating justified if wife argues with husband (1 = yes) & 0.557 & 11,631 \\
\hline Beating justified if wife refuses sex (1 = yes) & 0.544 & 11,360 \\
\hline Beating justified if wife burns food (1 = yes) & $\mathbf{2 0 , 8 8 2}$ & \\
\hline Women's acceptability of IPVAW score (0 - 1, percent out of 5) & \\
\hline $\begin{array}{l}\text { N } \\
\text { Notes: Each observation corresponds to a woman. }\end{array}$ & \\
\hline
\end{tabular}


Table 5. Odds Ratios of Facility Delivery and Antenatal Care Use, Ethiopia, 2005, 2011, 2016

\begin{tabular}{|l|l|l|}
\hline Variables & (1) Facility Delivery & $\begin{array}{r}\text { (2) Antenatal Care (WHO } \\
\text { Recommended } 8 \text { Visits) }\end{array}$ \\
\hline
\end{tabular}

\section{Main Exposures}

\begin{tabular}{|l|l|l|}
\hline Woman's autonomy score & $1.683(1.301-2.177)^{* * *}$ & $1.476(1.163-1.875)^{* * *}$ \\
\hline Women's acceptability of IPVAW score & $0.749(0.651-0.863)^{* * *}$ & $0.857(0.752-0.976)^{* *}$ \\
\hline
\end{tabular}

\section{Covariates}

\begin{tabular}{|l|c|c|}
\hline Wealth Quintile 2 & $1.517(1.277-1.804)^{* * *}$ & $1.174(1.009-1.365)^{* *}$ \\
\hline Wealth Quintile 3 & $1.231(1.014-1.493)^{* *}$ & $1.198(1.011-1.419)^{* *}$ \\
\hline Wealth Quintile 4 & $1.700(1.409-2.052)^{* * *}$ & $1.423(1.184-1.710)^{* * *}$ \\
\hline Wealth Quintile 5 & $2.215(1.700-2.656)^{* * *}$ & $1.286(1.016-1.629)^{* *}$ \\
\hline Education, Primary & $1.539(1.371-1.728)^{* * *}$ & $1.203(1.079-1.341)^{* * *}$ \\
\hline Education, Secondary & $2.739(2.271-3.303)^{* * *}$ & $1.435(1.183-1.741)^{* * *}$ \\
\hline Education, Higher & $4.656(3.146-6.892)^{* * *}$ & $1.185(0.900-1.560)$ \\
\hline Marital Status $(1=y e s)$ & $0.742(0.626-0.879)^{* * *}$ & $0.966(0.824-1.132)$ \\
\hline Birth Order & $0.820(0.790-0.851)^{* * *}$ & $0.936(0.909-0.964)^{* * *}$ \\
\hline Child Sex $(1=$ male) & $1.041(0.956-1.134)$ & $0.937(0.860-1.020)$ \\
\hline Urban $(1=$ yes) & $2.471(1.856-3.289)^{* * *}$ & $0.766(0.598-0.982)^{* *}$ \\
\hline Average wealth score & $1.470(1.322-1.635)^{* * *}$ & $1.188(1.083-1.302)^{* * *}$ \\
\hline Average schooling & $2.524(2.027-3.143)^{* * *}$ & $1.672(1.411-1.980)^{* * *}$ \\
\hline Quality score & & $407.0(317.4-521.9)^{* * *}$ \\
\hline Constant & $0.00849(0.00381-0.0189)^{* * *}$ & $0.0224(0.0103-0.0487)^{* * *}$ \\
\hline $\mathbf{N}$ & $\mathbf{2 0 , 8 8 2}$ & $\mathbf{2 0 , 8 5 1}$ \\
$* * * p<0.01, * * p<0.05, * p<0.1$ & &
\end{tabular}

Notes: The unit of observation is the birth. Odds ratios are presented with $95 \%$ confidence intervals in the parentheses below. Delivery in a facility (column 1) reports whether the mother delivered the birth in a health facility or not. ANC visits (column 2) reports whether the mother received at least 8 ANC visits for the birth. Results are from logistic regressions that include cluster, mother, birth, and quality of care controls. Cluster-level covariates are the average wealth index value of mothers in the cluster, and the average educational attainment of mothers in the cluster. Mother controls include the household wealth index (in quintiles), educational attainment of the mother (no education, primary, secondary, higher), age of the mother (in 5-year age groups), mother's marital status, and mother's place of residence (urban/rural). Birth level controls include birth order. For Column 2, quality of care controls include the 7-point average quality score that was generated for the birth. Standard errors are clustered at the primary sampling unit (DHS cluster) level.

Some community members and health providers expressed concern that cultural pressure for home birth and the quality of a woman's relationship with her husband could negatively impact her ability to use ANC, though these concerns were not always echoed by pregnant women.

"Development leaders in the community through Oneto-Five leaderships help and push all pregnant women to visit health facilities for check-ups... In the household, my husband encourages me to go to the health facilities. However, my husband's family [i.e. elders] do not encourage me to go to the health facilities for check-ups. In the community, women development army representatives encourage us."

IDI, pre-eclampsia survivor, rural
In Ethiopia, spouses/intimate partners, mothersin-law, and other family members play critical roles in determining whether and/or where women seek skilled care for ANC, delivery, and postnatal care (PNC). These relationships affect a woman's decisionmaking ability to adhere to treatment regimens and seek care. Husbands were described as both potential barriers and as enablers to motivating their wives' seeking health services.

"The primary one who motivates her to go to the health institution are HEWs...They follow up the pregnant mother from the beginning up to the time of delivery. The second one is the husband and it is a must for him. He is responsible to motivate her to go there. The neighbors are secondary... they should motivate and follow up this way."

FGD, male participant, urban 
Qualitative data elucidate manifestations of women's experiences of IPVAW and suggest plausible influences of these factors on access to maternal health services. Intimate partner dynamics occur in rural and urban settings, though were more pronounced in urban settings, where women experienced increased vulnerabilities to HIV, marital dispute, and potential separation and divorce. Some women describe sexual and physical violence during pregnancy, often describing consumption of alcohol as related to these acts.

"There are some husbands who even kick her while she is pregnant. Those husbands do not know the woman or the baby in her womb may get affected by their actions... there are two types: the one who assists [in getting to care] and beats that do not assist."

FGD, male participant, rural

I wasn't interested to have sexual intercourse with my husband while I was pregnant and he told me he wanted to. Then I told him that he couldn't force me into doing it. Then I turned away and slept on the bed, telling him not to touch me. He begged me, but I refused. Then he insulted me and threw me out of the bed."

FGD, female participant, urban

\section{CONCLUSIONS \& RECOMMENDATIONS}

Women in Ethiopia demonstrate some degree of decision-making power and autonomy. Although quantitative associations between women's autonomy and facility-based delivery and ANC use are statistically insignificant, qualitative evidence suggests that women, particularly young and urban women, have a strong sense of their personal autonomy and are willing to take charge of their health decision-making.

These women may however also be prey to gendered oppression by instances of IPVAW. The negative association between increased acceptability of IPVAW and ANC and delivery service utilization was stronger in Ethiopia than globally, in part due to higher proportions of women reporting normalized acceptable attitudes toward IPVAW.
Qualitative evidence corroborates complex gender dynamics, including the persistent influence of husbands, community members, and mothers-inlaw on women's health seeking behavior despite women's aspirations to make their own health-related decisions. Intimate partner violence reports from community members suggest that these dynamics may indirectly influence women's sense of safety and subsequent empowerment to seek necessary health care.

To further explore and understand the nuances of complex interpersonal and social dynamics, further research around maternal mental health as relates to perceptions and experiences of IPVAW is needed.

Explicit gender equity-promoting and socioeconomically supportive policy and programming should be explored to mitigate consequences of IPVAW and traditional social pressures, and empower women to use necessary maternal health care.

\section{REFERENCES}

1) Pooja Sripad, Charlotte E Warren, Michelle J Hindin, \& Mahesh Karra (2018). Assessing the role of women's autonomy and acceptability of intimate partner violence in maternal health-care utilization in 63 low- and middle-income countries. International Journal of Epidemiology, dyy299, https://doi.org/10.1093/ije/dyy299

\section{CONTACT}

Charlotte Warren, Senior Associate, Population
Council
cwarren@popcouncil.org
Pooja Sripad, Associate, Population Council
psripad@popcouncil.org
Charity Ndwiga, Program Officer, Population Council
cndwiga@popcouncil.org

The Ending Eclampsia project seeks to expand access to proven, underutilized interventions and commodities for the prevention, early detection, and treatment of pre-eclampsia and eclampsia and strengthen global partnerships. 